\title{
A INVISIBILIDADE DA CULTURA NEGRA BRASILEIRA ATRAVÉS DO DISCURSO DA "MESTIÇAGEM"1
}

\author{
THE INVISIBILITY OF BRAZILIAN BLACK CULTURE THROUGH THE \\ "MISCEgENATION" SPEECH
}

\author{
Bruno Marcelo de Souza Costa² \\ Paulo Jorge Martins Nunes ${ }^{3}$ \\ Piedade Lino Videira 4 \\ Elivaldo Serrão Custódio 5
}

\begin{abstract}
RESUMO: Este artigo tem como principal objetivo problematizar como a ideia de mestiçagem está muitas vezes ancorada de forma velada na tentativa de invizibilização da cultura negra no Brasil. O texto ora apresentado tenta problematizar o quanto o ideal de democracia racial emerge a partir do discurso velado de país mestiço-harmonioso e apresenta os mais expressivos intelectuais brasileiros, dentre eles Cavalleiro (2001) e Silva (2014), que discutem sobre o processo de branqueamento da sociedade brasileira. Todavia, é à luz de Kabengele Munanga que tentamos descortinar esse discurso ilusório e superficial da mestiçagem. As reflexões metodológicas que guiaram a escrita do artigo emergiram a partir de leituras sistemáticas e de discussões na disciplina Educação, Culturas e Diversidades, ministrada no Programa de Pós-Graduação em Educação da Universidade Federal do Amapá. Para nós, mestiçagem existe sim, mas foi usada como discurso ideológico e falacioso ao longo da história com o intuito de manter o poder da elite dominante e branca.
\end{abstract}

Palavras-chave: Mestiçagem. Brasil. Discurso. Racismo.

\footnotetext{
${ }^{1}$ Concepção de Mestiçagem a partir de Kabengele Munanga (2008).

2Doutor em Comunicação, Linguagens e Cultura pelo PPGCLC/UNAMA, Mestre pelo PPGARTES/ICA/UFPA. Professor das Redes Estadual e Municipal de Ensino do Estado do Amapá e 3Professor da Faculdade Madre Tereza -FAMAT-AP. Contato: bscosta82@hotmail.com ORCID http://orcid.org/0000-0003-2356-7926

${ }^{3}$ Doutor em Letras - Literaturas e Língua Portuguesa (Pontifícia Universidade Católica de Minas Gerais, Mestre em Teoria Literária pela mesma Universidade. Atualmente é professor da Universidade da Amazônia (UNAMA), onde integra o corpo docente do programa de Pós-Graduação em Comunicação, Linguagens e Cultura (Mestrado e Doutorado). Contato: pontedogalo3@gmail.com ORCID http://orcid.org/0000-0001-7238-702X

${ }^{4}$ Doutora e Mestre em Educação Brasileira (Universidade Federal do Ceará UFC). Professora Adjunta da Universidade Federal do Amapá (UNIFAP) no Mestrado em Educação. Líder do Grupo de Estudo, Pesquisa, Extensão e Intervenção em Corporeidade, Artes, Cultura e Relações Étnico-raciais com ênfase em Educação Quilombola certificado pelo CNPq. Coordenadora-Geral do Núcleo de Estudos Afro-brasileiros - NEAB/UNIFAP. Contato: piedadevideira@bol.com.br ORCID http://orcid.org/0000-0001-5325-9073

${ }^{5}$ Doutor em Teologia pela Faculdades EST, em São Leopoldo/RS. Pós-doutor em Educação pela Universidade Federal do Amapá (UNIFAP). Atualmente é professor permanente no Mestrado em Educação da UNIFAP. Vice-líder do Grupo de Pesquisa Educação, Interculturalidade e Relações Étnico-Raciais (UNIFAP/CNPq). Contato: elivaldo.pa@hotmail.com ORCID http://orcid.org/00000002-2947-5347
} 
ABSTRACT: The main objective of this article is to problematize how the idea of miscegenation is often anchored in a veiled way in an attempt to make black culture invisible in Brazil. The text now presented tries to problematize how much the ideal of racial democracy emerges from the veiled discourse of a mestizo-harmonious country and presents the most expressive Brazilian intellectuals, among them Cavalleiro (2001) and Silva (2014), who discuss the process of laundering of Brazilian society. However, it is in the light of Kabengele Munanga that we try to unveil this illusory and superficial discourse of miscegenation. The methodological reflections that guided the writing of the article emerged from systematic readings and discussions in the discipline Education, Cultures and Diversities, taught in the Graduate Program in Education at the Federal University of Amapá. For us, miscegenation does exist, but it has been used as an ideological and fallacious discourse throughout history in order to maintain the power of the dominant and white elite.

Keywords: Miscegenation. Brazil. Speech. Racism.

\section{Situando o leitor}

Como já muito estudado e debatido, sabemos que o Brasil é um país multi e pluricultural, o qual foi constituído a partir da presença de várias raças ou etnias, dentre as quais as que mais se destacam nos estudos são: o branco (majoritariamente e simbolicamente representado pelo português), os índios (indivíduos que habitavam nossas terras quando os portugueses aqui chegaram) e os africanos negros (indivíduos importados sob regime de escravidão). Podemos, então, inferir que nosso país tem um sentido de mestiçagem muito marcado e visível. É a partir desse pensamento que se dá a reflexão proposta desse artigo, mas antes cabe uma melhor contextualização do objeto.

A presente discussão é parte das reflexões iniciais do projeto de pesquisa da tese de doutoramento que trata de maneira geral a representação do negro na televisão brasileira, especificamente em programas humorísticos da Rede Globo de Televisão, num recorte temporal que vai desde 1975 até 2015, totalizando 40 anos analisados. Na tentativa de elucidar e escrever sobre o que nos propomos na tese é que emerge a tessitura desse artigo.

Como trataremos do negro na televisão brasileira, é de fundamental importância entender/compreender o processo de diáspora do negro no Brasil para assim compreender pontos nefrálgicos de nossa pesquisa. Além disso, para caminhar de maneira introdutória desse objeto de tese, é necessário também 
pensar sobre os processos de mestiçagem que envolve e, por vezes, aniquila a cultura afro-brasileira.

Partindo dessa ideia, este artigo tem como objetivo dissertar e compreender os processos de mestiçagem e principalmente suas reverberações na cultura negra brasileira. Já adiantamos que partimos da perspectiva de Kabengele Munanga, que defende a tese de que muitas vezes o discurso de um país mestiço ou híbrido aniquila de forma violenta e preconceituosa a cultura negra e/ou afro-brasileira.

Neste texto especificamente apoiamo-nos teoricamente em: Munanga e Gomes (2006), Munanga (1986, 2008), Cavalleiro (2001), Silva (2014), todos eles teóricos que abordam as questões étnico-raciais em suas pesquisas. Além disso, salientamos que as discussões emergidas são também oriundas da disciplina Educação, Culturas e Diversidades, realizada no programa de Pós-graduação em Educação da Universidade Federal do Amapá (UNIFAP) que ajudaram de forma profícua na elaboração dessa reflexão.

Metodologicamente, o artigo é de caráter reflexivo e bibliográfico, tendo como objeto de estudo, especificamente, a compreensão sobre os conceitos de mestiçagem a partir de Munanga e Gomes (2006), refletindo de forma crítica sobre como esse discurso foi usado para camuflar uma falsa ideia de democracia racial, reverberando assim num aniquilamento da cultura afro brasileira.

Para tanto, o artigo tem com corpo estrutural os seguintes eixos: no primeiro tópico, apresentamos conceitos preliminares de mestiçagem, desembocando no pensamento brasileiro sobre mestiçagem; logo em seguida, tentamos, de forma ensaística preliminar, apresentar como o discurso de mestiçagem gera uma cultura de recalque e negação do povo negro; e, por último, apresentamos um tópico intitulado "O racismo velado e a (des) construção da Identidade Negra", no qual abordamos questões sobre racismo e como a identidade negra muitas vezes é afetada de forma negativa pelo sistema hegemônico dominante.

\section{Conceitos preliminares acerca da mestiçagem}

Munanga (2008) diz que a mestiçagem é um fenômeno universal ao quais as populações ou conjuntos de populações só escapam por períodos limitados. Para ele, a mestiçagem é concebida como uma troca ou um fluxo de genes de 
intensidade e duração variáveis entre populações mais ou menos contrastadas biologicamente. No entanto, Munanga esclarece que o ponto de vista ideológico nesse construto de raça interfere no ponto de vista biológico, chegando em muitos momentos a definir categorias ou seja, biologizando o indivíduo mestiço. Vejamos:

\begin{abstract}
O que significa ser branco, ser negro, ser amarelo, ser mestiço, ou homem de cor? Para o senso comum, essas denominações parecem resultar da evidência e recobrir realidades biológicas que se impõem por si mesmas. No entanto, trata-se, de fato, de categorias cognitivas largamente herdadas da história da colonização, apesar da nossa percepção da diferença situar-se no campo do visível. É através dessas categorias cognitivas, cujo conteúdo é mais ideológico do que biológico, que adquirimos o hábito de pensar nossas identidades sem nos darmos conta da manipulação do biológico pelo ideológico (MUNANGA, 2008, p. 18).
\end{abstract}

A partir desse enfoque, percebe-se que a mestiçagem não pode ser vista apenas pelo enfoque biológico, tendo em vista que seus conteúdos e determinações são afetados/influenciados pelas ideias e representações que esses indivíduos fazem e constroem socialmente através de comportamentos e jeitos de ser e estar no mundo. "A noção de mestiçagem, cujo uso é ao mesmo tempo cientifico e popular, está saturada de ideologia" (MUNANGA, 2008, p. 18). É nessa análise que reside o duplo sentido da mestiçagem.

Para o campo das ciências humanas, é menos tortuoso e mais crítico partir para a discussão sociológica desses fatos, sabemos das generalidades de todos os casos de cruzamento ou miscigenação entre populações biologicamente diferentes, no entanto centra-se aqui a análise não sobre o fenômeno biológico enquanto tal e sim sobre os fatos sociais, psicológicos, econômicos e político-ideológicos decorrentes desse fenômeno biológico inerente à história evolutiva da humanidade. Como retrata Munanga,

Seria totalmente errôneo representar graficamente essa história sob a forma de uma árvore e suas ramificações. Pois bem, se as ramificações de uma árvore representada por seus inúmeros galhos não se cruzam, a história da humanidade apresenta um gráfico diferente, no qual os galhos se cruzam (MUNANGA, 2008, p. 21).

Parafraseando Munanga, podemos dizer que o Brasil é um desses muitos galhos que se intercruzam com outros galhos dessa grande árvore. Dessa forma, passemos ao pensamento brasileiro sobre a ideia de mestiçagem. Muitos 
estudiosos pensaram essa problemática, dentre eles podemos citar: Sílvio Romero, Joao Batista Lacerda, Nina Rodrigues, Euclides da Cunha, Oliveira Viana e Gilberto Freyre, entre outros.

Munanga (2008), em sua obra "Rediscutindo a mestiçagem no Brasil", traça um breve panorama sobre como esses intelectuais brasileiros pensavam a questão da mestiçagem e quais as suas previsões para o futuro do Brasil. De pronto, é notório que todos eles acreditavam numa suposta superioridade da "raça" branca. Desta forma, esses intelectuais abordavam a mestiçagem na tentativa de elucidar uma suposta fase de transição da população brasileira, ou usavam o discurso falacioso de democracia racial a partir da ideia de país mestiço. Vejamos os eixos principais de cada pensamento.

Sílvio Romero acreditava que a mestiçagem era uma fase de transição e que levaria a população brasileira a um embranquecimento nas futuras gerações. $O$ autor também acreditava na formação de um tipo racial nacional único, ideia que rendeu ao intelectual inúmeras críticas de outros intelectuais que não acreditavam nessa formação de um tipo único racial (MUNANGA, 2008).

Dentre os intelectuais que teceram críticas a Sílvio Romero estava Raimundo Nina Rodrigues, para quem a institucionalização e a legislação da diferença era o único caminho para responder à dificuldade de construção de uma identidade nacional. Com uma dose profunda de atavismo em seu discurso, Rodrigues (1938) não vê no mestiço um caminho que levasse mais cedo ou mais tarde a um país branco. Segundo ele, a influência do negro sempre haveria de aparecer de forma a salientar as negatividades da "raça". De certo modo, Rodrigues vê na mestiçagem um produto e um resultado inverso ao que previa Sílvio Romero, em vez de um embraquecimento, ele via o enegrecimento.

Euclides da Cunha é outro intelectual que discorda de Romero. Vejamos o cerne de seu pensamento em Munanga (2008):

[...] existem vários tipos devido à heterogeneidade racial, aos cruzamentos, ao meio físico e à variedade de situações históricas. Para ele, o mestiço, traço de união entre raças, é quase sempre um desequilibrado, um decaído, sem a energia física dos ascendentes selvagens e sem a atitude intelectual dos ancestrais superiores (MUNANGA, 2008, p. 54). 
Um dos pontos mais preconceituosos dentro do pensamento de Cunha é à volta à ideia de atavismo, já trazido à tona por Nina Rodrigues. É a partir desse conceito que Cunha se utiliza para explicar a instabilidade de mestiço, atribuindo a essa instabilidade a presença do sangue negro. Segundo Munanga (2008), o Brasil não pode ser considerado como um povo, uma nação, porque é etimologicamente indefinido por falta de tradições nacionais uniformes.

É importante ressaltar mais uma vez o caráter preconceituoso de Euclides da Cunha, para quem as características principais do mestiço resultariam das negatividades oriundas dos negros: "quanto ao africano, não há esforços que consigam aproximá-lo sequer do nível intelectual do indo-europeu" (MUNANGA, 2008, p. 56). Desta forma, podemos inferir que tanto Cunha quanto Romero aderiram ao conceito de raças superiores e inferiores e em ambos é possível notar o racismo enubriado na ideia de mestiçagem.

Outro intelectual importante nesse processo de discussão sobre mestiçagem é Joao Batista Lacerda, o qual, apesar de enaltecer a posição de contribuição dos mestiços para o Brasil, deixa transparecer um viés racista para com o povo negro. Vejamos o que diz Munanga (2008, p. 60) sobre o pensamento do autor:

Considerava os mestiços obviamente inferiores aos negros como mão de obra agrícola e tendo pouca resistência às moléstias. Porém, física e intelectualmente, ele os considerava acima do novel dos negros. Rejeitando a teoria de que os fatores relativos à hibridização de animais podiam ser aplicados a seres humanos, ele pensava que o cruzamento de preto com branco não produz geralmente progenitura de qualidade intelectual inferior.

Lacerda também acreditava que os filhos de mestiços no Brasil apresentariam na terceira geração caracteres físico da raça branca, alguns, por conta do atavismo, retêm poucos traços de sua ascendência negra, mas as miscigenações removem dos descendentes dos mestiços as características negras. Em razão desse pensamento, é possível inferir e pensar que o caminho da população brasileira era o embranquecimento e que os mestiços desapareceriam, isso coincidiria com a extinção da raça negra em nosso país.

Gilberto Freyre é outro intelectual que merece destaque nesse cenário. Um ponto nevrálgico no seu pensamento é a consolidação do mito das três raças, Freyre, portanto, nos traz a ideia da mestiçagem como uma vantagem imensa. Ele 
transforma a mestiçagem em valor positivo e não negativo sob o aspecto da degenerescência. O autor permitiu completar definitivamente os contornos de uma identidade que há muito vinha sendo desenhada. Foi a partir desse pensamento que Freyre faz brotar a ideia da democracia racial. "Somos uma democracia porque a mistura gerou um povo sem barreira, sem preconceito" (MUNANGA, 2008, p. 77). Seguindo essa linha de pensamento:

O mito da democracia racial, baseado na dupla mestiçagem biológica e cultural entre as raças originarias, tem uma penetração muito profunda na sociedade brasileira: exalta a ideia de convivência harmoniosa entre os indivíduos de todas as camadas sociais e grupos étnicos, permitindo às elites dominantes dissimular as desigualdades e impedindo os membros das comunidades nãobrancas de terem consciência dos sutis mecanismos de exclusão da qual são vítimas na sociedade (MUNANGA, 2008, p. 77).

Percebermos em Freyre uma lacuna de análise, a ideia de mestiçagem como algo positivo é usada para mascarar o preconceito e o permanente domínio da comunidade não negra no Brasil. O mito da democracia racial foi insurgido nesse período e permanece vivo em nossa sociedade até os dias atuais.

Munanga (2008) tece duras críticas a Freyre quando diz que este não leva em consideração em suas análises à relação assimétrica de poder entre senhores e escravos, da qual surgiram os primeiros mestiços. Para Munanga, ao mesmo tempo em que Freyre defendia a cultura negra como elemento básico da formação nacional brasileira, ele preconizava um universalismo ambíguo, temperado pelo conceito de meia-raça.

Por fim, chegamos ao nome de Francisco José de Oliveira Viana, o qual foi elencado por último de forma proposital, visto que, sem sombra de dúvida, é o intelectual mais referido nos debates de embranquecimento da sociedade brasileira. Viana sistematizou um complexo de ideias racistas que depois foram superadas pelos progressos da antropologia de sua época. Vejamos os principais pontos de sua teoria.

Viana acreditava em classificações dos mulatos. Para ele, existia o mulato inferior e o superior. O primeiro era resultado do branco com o negro do tipo inferior, e o segundo é resultado do cruzamento do branco e do negro do tipo 
superior, sendo este considerado ariano pelo caráter e pela inteligência. Sintetizando:

Os mestiços 'superiores' conseguiram, por meio de casamentos e pela posse da terra nos novos núcleos, incorporar-se à classe superior, à nobreza territorial, usando a sua identificação com a aristocracia rural pela similitude de caráter, de conduta e, principalmente, de cor. Os mestiços inferiores, os menos dissimulados, os facilmente reconhecíveis, os estigmatizados, os cabras [...]. Esses foram implacavelmente eliminados (MUNANGA, 2008, p. 65).

Munanga (2008, p. 66) tece duras críticas a Viana:

Fica bastante difícil para nós entendermos como Viana conseguiu inventar indivíduos que, por mais miscigenados que fossem, tivessem mentalidades justapostas na cabeça, e essa justaposição se faz de acordo com a origem dos seus ancestrais. Também fica difícil entender como ele ignorou que o contexto colonial não podia favorecer as possibilidades de ascensão, cuja falta ele joga no negro, índio e mestiço. Em vez de criticar a situação colonial e o colonizador, que reprimiram as oportunidades de manifestação dessa vontade, ele encontra a explicação na psicologia da própria vítima.

Viana é, portanto, um dos grandes protagonistas da construção da ideologia racial brasileira, caracterizada pelo ideal do branqueamento que Oracy Nogueira (MUNANGA, 2008) teve mais tarde o mérito de configurar como preconceito de marca ou de cor em oposição ao preconceito de origem, baseado numa gota de sangue vigente nos Estados Unidos.

O que importa para as conclusões sociológicas, disse Viana (MUNANGA, 2008), não é tanto determinar o tipo puro (genótipo), mas sim o tipo aparente (fenótipo). Com efeito, têm-se duas espécies de brancos: o branco puro (genótipo) e o branco aparente (fenótipo), isto é, o mestiço brancóide, de aspecto ariano (fenótipo) (MUNANGA, 2008). Munanga (2008) ao se referir ainda a Viana, expressa que os elementos bárbaros da sociedade brasileira iam aos poucos desaparecer devido ao estacionamento do crescimento da população negra e ao aumento contínuo dos arianos, cuja qualidade de sangue crescia cada vez mais, no sentido de refinamento mais apurado da raça.

Descortinando esse pensamento de Viana, verificamos que a ideia de inferioridade do negro está presente sempre, sendo os valores negativos do 
mestiço quase sempre ligados à ascendência negra. Disso, Munanga discorda veementemente. Segundo o raciocínio de Viana, tudo levaria a crer que o processo de arianização ia, a longo prazo, terminar aparentemente no embranquecimento da população e, consequentemente, numa situação em que não existisse mais a linha de cor, pelo menos para os brancos aparentemente genotipicamente.

Dentro desse contexto, é necessário dizer que existiram vozes intelectuais discordantes, dentre elas estão: Alberto Torres (1982), Manuel Bonfim (1997) e Roquete-Pinto (1978), que defendiam a tese de que a unidade nacional num novo país surgido da colonização era de natureza sociológica, ou seja, políticoeconômica e jamais racial. Para eles, o verdadeiro problema do país era a exploração por estrangeiros, cuja rapidez levava ao esgotamento dos recursos naturais a uma taxa alarmante, ao crescente controle dos setores dinâmicos da economia por capitalistas e estrangeiros e ao abandono sistemático da população nacional em favor de imigrantes que recebiam privilégios especiais.

$\mathrm{Na}$ verdade, os três intelectuais buscavam explicar o atraso brasileiro a partir de outros ângulos. No entanto, sabemos do esforço para legitimar que, no Brasil, a questão da cor não é um problema, o que se percebe é apenas um atenuamento das questões raciais, mas que, na verdade, estão presentes de forma quase que naturalizada.

\section{O discurso da mestiçagem e a cultura negra brasileira}

Vários autores definem o Brasil como um país mestiço, dessa forma fica muito complexo percebermos ao certo o grau de contribuição de cada cultura que aqui se fez/faz presente. Essa complexidade, em muitos momentos, faz com que subalternizemos a cultura negra, afinal há muito tempo os negros foram considerados inferiores, inclusive a categoria "mestiço" veio ratificar isso nos estudos de Kabengele Munanga, como já discorrido no tópico anterior.

Nesta seção, o intento é sobrevoar o discurso da mestiçagem e a cultura negra e refletir sobre a maneira como esse discurso invisibiliza o negro, ou, ainda, faz com que muitos pensem como Sílvio Romero, que acredita que essa 
mestiçagem resultaria num embranquecimento da população brasileira, só assim então constituindo uma verdadeira nação.

Munanga, em seu livro Rediscutindo a mestiçagem no Brasil: identidade nacional versus identidade negra, publicado em 2008, faz uma análise no tópico intitulado Ambiguidade de raça/classe e a mestiçagem como mecanismos de aniquilação da identidade negra e afro-brasileira que consideramos muito pertinente, pois traça paralelos entre a mestiçagem ocorrida no Brasil e a de outros países, em especial nos Estados Unidos.

De acordo com Munanga (2008), os homens brancos preocupavam-se de certa forma como seus filhos mestiços, frutos de seus descuidos sexuais com mulheres escravas. Isso certamente influenciaria no que chamamos aqui de categorização de pessoas: os filhos protegidos, apesar de "mestiços" ou "mulatos", desempenhavam um papel social acima de negros escravos, contribuindo para o enfraquecimento do sentimento de solidariedade entre eles e os negros.

Outro ponto importante nessa questão é que os negros acreditavam que seus filhos pudessem quebrar ou furar as barreiras do preconceito caso se casassem com brancos, embranquecendo então seus descendentes. Segundo Munanga (2008, p. 81) "tal situação atua como uma válvula de segurança sobre o descontentamento e frustração entre os negros e os mulatos", razão pela qual se gerou uma falta de mobilização e protestos organizados de forma mais contundente no Brasil.

O surgimento, então, da categoria mestiço ou mulato, no Brasil, cria de certa forma um apagamento e uma luta invisível para sair da categoria "negro", vista como subalterna e inferior; era melhor, portanto, ser mestiço ou mulato do que ser negro, pois o mestiço poderia ser embranquecido e enquadrado no status superior, ou seja, existia uma zona intermediária, fluida e vaga que flutua até certo ponto ao sabor do observador ou das situações postas. Assim como também os mestiços com características físicas negras disfarçáveis, principalmente quando possuíam atributos que implicavam em status médio ou elevado (diploma de nível superior, riquezas e outros), poderiam ser incorporados na categoria "brancos". Continuemos nessa reflexão via Munanga (2008, p. 83):

No Brasil, a percepção da cor e de outros traços negroides é 'gestáltica', dependendo, em grande parte, da tomada de consciência dos mesmos pelo observador, do contexto de elementos 
não-raciais (sociais, culturais, psicológicos e econômicos) e que estejam associados - maneiras, educação sistemática, formação profissional, estilo e padrão de vida -, tudo isso obviamente ligado à posição de classe, ao poder econômico e à socialização daí decorrente.

Para Munanga (2008), a maioria da população afro-brasileira vive nessa tal zona intermediária, sonhando em conquistar o status de ser "branco". Fanon (2008) também aborda essas questões em seu livro Pele negras máscaras brancas, no qual aponta que o sonho do martinicano negro é tornar-se branco, é como se fosse uma espécie de cultura de recalque impregnada de forma violenta e colonizadora em nossas mentes, segundo a qual o ideal é ser branco ou pelo menos ser como os brancos. Nesse sentido, surge a ideia de estudiosos norteamericanos, de acordo com a qual o brasileiro pode mudar de raça, ou melhor, de identificação racial, no percurso de sua vida.

\begin{abstract}
Essa interpretação se aproxima dos ditados populares 'o dinheiro branqueia' e 'o preto rico é branco' ou 'branco pobre é preto'. Por isso, Oracy Nogueira pede cuidado na interpretação desses ditos, que são sempre empregados com certa ironia e cujo sentido mais exato seria: 'o dinheiro compra tudo, até o status para o negro', o que, segundo ele, está longe de ser uma negação do preconceito ou da discriminação (MUNANGA, 2008, p. 84).
\end{abstract}

Harris (1967) acredita que essa hireraquização racial brasileira baseada na cor ou na marca é ambígua, na medida em que expressa pouco a importância da identidade racial em contraposição com a importância assumida pela classe. A determinação da classe, então, passa a ser fator fundamental para o enquadramento da raça à qual pertencemos, o que justificaria as "desconfianças" e frases preconceituosas do tipo "Nossa! Ele tem esse carro!" quando o carro em questão é de propriedade de um negro.

Cabe então questionarmos essas concepções postas como regime de verdade que colocam ainda hoje a "branquitude" como padrão intelectual, estético, discursivo, acadêmico, etc. Portanto, trata-se de reconhecer que a contribuição dos movimentos negros é a condição de possibilidade de uma leitura realmente crítica do racismo hoje e de questionamento de um regime de verdade que se pretende não-marcado - e por isso, um padrão pretensamente universal nas 
percepções de mundo -, aquele relacionado à manutenção da "cultura da branquitude" e do "prestígio branco".

É essencial apontar que o argumento da complexidade de classificação racial e da mestiçagem, aquele famoso bordão "aqui somos todos miscigenados e é impossível saber quem é branco ou preto porque somos todos miscigenados" nunca ajudou a solucionar o problema do racismo na sociedade brasileira e tampouco contribuiu para a união das vítimas do racismo.

Pelo contrário. Enaltecer a ambiguidade racial e a mestiçagem sempre foi às estratégias escolhidas, em sua maioria, pelas elites intelectuais e políticas brasileiras, desde a década de 1930, e o discurso da mestiçagem foi e continua sendo utilizado como instrumento ideológico que desconstrói a luta por direitos iguais entre negros e brancos. A mestiçagem, apesar de ser um fato da humanidade como um todo, não apaga as desigualdades entre brancos e negros.

Concluímos esse tópico com uma citação de um pensador afro-brasileiro Abdias do Nascimento que deixou sua marca e contribuição na luta contra o desvelamento do preconceito contra o negro no Brasil:

\begin{abstract}
A história não oficial do Brasil registra o longo e antigo genocídio que se vem perpetrando contra o afro-brasileiro. Monstruosa máquina ironicamente designada 'democracia racial' que só concede aos negros um único privilégio': aquele de se tornarem brancos, por dentro e por fora. A palavra-senha desse imperialismo da brancura, e do capitalismo que the é inerente, responde a apelidos bastardos como assimilação, aculturação, miscigenação; mas sabemos que embaixo da superfície teórica permanece intocada a crença na inferioridade do africano e seus descendentes (NASCIMENTO, 1978, p. 93).
\end{abstract}

O autor corrobora com a ideia de que os negros têm sua cultura devastada pela hegemonia branca, a qual logo se encarrega de criar vários mecanismos para velar essa forma brutal de preconceito, como nos diz Abdias do Nascimento, para o negro o único privilegio que é reservado é o de torna-se branco.

\title{
3. O racismo velado e (des)construção da identidade negra
}

Acreditamos que até aqui fica evidente o papel da mestiçagem na (des) construção da identidade negra. A elite pensante brasileira tinha clareza de suas 
ações e das reverberações e justificativas para a mestiçagem. Além disso, também sabia que precisaria anular a superioridade numérica do negro e alienar os descendentes mestiços para assim fortalecer a ideologia do branqueamento, tentando evitar, dessa forma, prováveis conflitos raciais conhecidos em outros países. Tal atitude fortaleceu o tipo de preconceito e racismo existente no Brasil, o racismo velado.

São décadas de impregnação da cultura da inferioridade, isso repercute em todos os campos sociais de representação do brasileiro. São anos e anos de submissão, de secundarismo, de invisibilidade, são anos também que muitos negros aceitam sua condição de menos, de pior. Hoje, no Brasil, os negros são maioria numérica, mas infelizmente é minoria político-social. Repensar esses dados que estão postos é tarefa primária para uma sociedade que se esconde atrás do mito da democracia racial.

O racismo no Brasil se dá de um modo diferente de outros contextos, apoiado em uma constante contradição. Pesquisas, histórias de vida, conversas e vivências cotidianas revelam que ainda existe racismo em nosso país, mas a sociedade brasileira, de maneira genérica, não aceita que tal realidade seja posta como "verdade". Dessa forma, quanto mais a população, a escola e o poder institucional negam a lamentável presença do racismo, mais ele se dissemina e invade as mentalidades, as subjetividades e as condições sociais e educacionais dos negros. Nessa mesma corrente de pensamento, Cavalleiro (2001, p. 76) diz:

\begin{abstract}
Nos dias atuais, o racismo tem se manifestado de maneira muito evidente, quando se tenta negar a humanidade das pessoas negras, comparando-as por meio de seus atributos físicos a coisas, doenças e animais. Essas comparações são naturalizadas na cultura brasileira, ou seja, de tanto inferiorizar as pessoas negras com apelidos, 'piadinhas' e gracejos, seguidos de 'tapinhas' nas costas e comentários sobre os/as amigos/as negros/as que até frequentam a casa das pessoas brancas, bem como as trabalhadoras domésticas negras, 'tratadas como filhas', todo mundo passa a achar que isso é engraçado, louvável e quem se indigna é 'neurótico/a'.
\end{abstract}

Assim, a primeira dificuldade brasileira na luta contra o racismo é assumir sua existência. Cavalleiro (2001), em sua obra Racismo e anti-racismo na educação: repesando nossa escola, nos coloca essa problemática como ponto de amarração para darmos conta de uma educação não excludente. Para tanto, 
precisamos assumir nossa mestiçagem, mas não usá-la como instrumento para inviabilizar mais uma vez a cultura negra de nossa sociedade. Por isso, descortinar esse conceito requer repensarmos em que lugar a mestiçagem colocou o negro e o índio.

Nesse sentido, no ideal falacioso de convivência harmônica entre os "mestiços", muitas pessoas se negam preconceituosas. Entretanto, constatamos que, ao perguntar para essas pessoas se permitiriam que suas filhas casassem com negros, a primeira resposta é não. Em outra situação, ao verem uma mulher branca casada com um homem negro, deduzem que, certamente, este homem tem dinheiro; ou, ainda, quando encontram um homem negro dirigindo um carro caro, acreditam que, sem dúvida, ele é o motorista. Quantas vezes essas situações já não se fizeram presentes em nossas vidas cotidianas?

O negro é sempre subalternizado, e isso também se explica nas teorias racistas da mestiçagem, segundo as quais a cor da pele é classificação para ocupar determinado lugar na sociedade. "Ninguém nasce com preconceitos: eles são aprendidos socialmente, no convívio com outras pessoas" (MUNANGA; GOMES, 2006, p. 182). A perpetuação do preconceito racial em nosso país revela a presença de um sistema social racista que possui mecanismos para produzir as desigualdades raciais dentro da sociedade.

Dessa forma, identificamos em nossa sociedade sempre uma tentativa de apagamento da identidade negra em detrimento de uma política do embranquecimento. Por isso é necessário ampliarmos o debate para o que diz respeito à construção da identidade e da diferença. Silva (2014) nos diz que mais do que celebradas, elas devem ser questionadas e problematizadas, tendo em vista que elas se constroem e reconstroem cultural e socialmente.

Para Silva (2014), a princípio, a diferença só existe porque existe uma identidade referencial. Depois o autor nos leva a outra:

Em geral, consideramos a diferença como produto derivado da identidade. Nesta perspectiva, a identidade é a referência, é o ponto original relativamente ao qual se define a diferença. Isto reflete a tendência a tomar aquilo que somos como sendo a norma pela qual descrevemos ou avaliamos aquilo que não somos. Por sua vez, na perspectiva que venho tentando desenvolver, identidade e diferença são vistas como mutuamente determinadas. Numa visão mais radical, entretanto, seria possível dizer que, contrariamente à primeira perspectiva, é a diferença que vem em primeiro lugar. Para 
isso seria preciso considerar não simplesmente como resultado de um processo, mas como o processo mesmo pelo qual tanto a identidade quanto a diferença (compreendida aqui como resultado) são produzidas (SILVA, 2014, p. 76).

Pensando a identidade negra brasileira como algo produzido pela diferença de um todo, podemos inferir e concordar com Tomas Tadeu Silva quando nos relata que identidade e diferença são "criaturas da linguagem". Apesar de saber das diferenças, a sociedade brasileira viveu/vive com uma necessidade de unificação racial e cultural imposta desde há muito tempo.

Nessa imposição, a mestiçagem foi um fator que serviu de instrumento para legitimar raças superiores e inferiores, e, nesse processo de legitimação, os negros tiveram seus valores e ancestralidades esmagados pelo colonizador, perpetuando assim a própria negação da "raça". Fanon (2008) esclarece o suposto complexo de inferioridade do negro em relação ao branco e o processo perverso que têm suas bases na história, na sociologia, reverberando até mesmo em questões psicológicas.

Mas, voltemos para a questão da identidade e diferença. É certo que esta marcação de identidade e diferença sempre implicam em relações que excluem e incluem. Quando dizemos o que somos automaticamente dizemos o que não somos, e isto se aplica de alguma forma à falta de afirmação da identidade negra brasileira. Quando detectamos um certo receio de se auto declarar negras, as pessoas empregam certos "atenuantes", usando assim a discursividade para negar suas ancestralidades.

Afirmar a identidade significa demarcar fronteiras, significa fazer distinções entre o que fica dentro e o que fica fora. A identidade está sempre ligada a uma forte separação entre 'nós' e 'eles'. Essa demarcação de fronteiras, essa separação e distinção, supõem e, ao mesmo tempo, afirmam e reafirmam relações de poder. "Nos" e eles não são, neste caso, simples distinções gramaticais (SILVA, 2014, p. 82).

Essa relação de poder que nos sugere Silva (2014) é evidente na sociedade brasileira. O autor segue nos dizendo que a identidade e a diferença estão estreitamente ligadas às maneiras pelas quais a sociedade produz e utiliza suas classificações. Com base nesse argumento, podemos dizer que nossa sociedade 
faz uso evidente de classificações sociais a partir da cor da pele, fazendo assim da cor da pele instrumento de preconceito e discriminação. Talvez por isso o discurso de mestiçagem para o movimento negro não cabe, não cabe por uma questão política e social de luta pela afirmação de uma identidade/diferença que foi/é apagada.

Para concluir este tópico, é necessário dizer que a sociedade brasileira utilizou/utiliza padrões de identidade como normas a serem seguidas, e o mais interessante é que isso se dá de forma velada, mas acontece em todos os âmbitos sociais e cultuais brasileiros, vide novelas, comercias de TV, discursos jornalísticos, jargões humorísticos, padrões estabelecidos socialmente de beleza estética e física, elementos culturais e religiosos e por aí seguimos com rastros dessa falsa democracia racial que vivemos. Como diz Silva (2014, p. 83), "fixar uma identidade como a norma é uma das formas privilegiadas de hierarquização das identidades e das diferenças".

Normalizar essa identidade significa atribuir a ela todas as características positivas possíveis, em relação às quais as outras identidades só podem ser avaliadas de forma negativa. É nesse processo que se encontra a identidade negra no Brasil, por isso a necessidade de visibilizarmos e dar voz aos corpos negros brasileiros e junto com eles a todas as suas ancestralidades.

\section{Considerações finais}

Não se pode negar que a mestiçagem existe em nosso país. A sociedade brasileira é sim miscigenada e como muitas tonalidades de "cor" e de hábitos. No entanto, também é inegável que a mestiçagem foi instrumento de aniquilamento da cultura negra, haja visto que o Brasil sempre priorizou os cânones europeus como "padrão", sendo impossível para as minorias políticas se insurgirem contra o poder hegemônico que se fazia/faz presente. É certo que isso vem mudando ao longo da história e, aos poucos, os negros estão conseguindo refazer e reconhecer suas identidades e ancestralidades africanas, mas a luta ainda é árdua.

É importante também enaltecer que muitos teóricos latinos contemporâneos já tentaram redefinir o conceito de mestiçagem num campo mais antropológico e sociológico, abandonando a biologia. Muitos termos já são usados para "definir" misturas: hibridização, crioulização, transculturação e outros menos conhecidos. 
Entretanto, para a sociedade brasileira, esse ponto ainda é muito caro, porque trata de definir nação, e, para um país como o nosso, essa tarefa e árdua, como nos diz Da Matta (1986): "o que faz brasil, Brasil?".

Os dados mais atuais do Instituo Brasileiro de Geografia e Estatística (IBGE) comprovam que a maioria da população brasileira é negra (IBGE, 2019); no entanto, esse ganho quantitativo não reverbera nas representações sociais positivas. Ainda notamos os efeitos da política do embraquecimento nos próprios negros, que não se reafirmam como deveria ser, seguem uma cultura de recalque, negando muitas vezes sua própria identidade.

A ideia de mestiçagem também evidenciou preconceitos, trazendo à tona a questão do racismo à brasileira, ou como já definido incialmente por Viana, o racismo de marca. Nossa sociedade clamava/clama pelo embraquecimento como se o sangue negro fosse um estigma negativo que devesse ser apagado de nossas memórias e de nossos corpos. Como, porém, fazer isso, se esses mesmos corpos já estão impregnados de movimento e africanidades, nosso vocabulário está tomado por essas influências, nossas crenças religiosas sincréticas possuem uma contribuição significativa da cultura negra, nossos vários tons de pele refletem nossos jeitos de ser estar no mundo de maneira diversa e plural?

Para finalizar, ratificamos que a ideia de mestiçagem usada para legitimar o discurso falacioso de país harmonioso e livre de preconceitos precisa ser olhada minimamente com um olhar mais crítico, principalmente pelos movimentos negros organizados. Munanga nos adverte nesse sentido, enfatiza que esse discurso serviu/serve para subalternizar, apagar, invisibilizar, "tornar menor" todos os possíveis traços e hábitos culturais da população negra no Brasil.

\section{Referências}

BONFIM, Manuel. O Brasil na América: caracterização da formação brasileira. 2.ed. Prefácio de Maria Thétis Nunes. Rio de Janeiro: Topbooks, 1997.

BRASIL. Instituto Brasileiro de Geografia e Estatística (IBGE). Pesquisa nacional por amostra de domicílios: síntese de indicadores. Rio de Janeiro: IBGE, 2019. Disponível em: http://biblioteca.ibge.gov.br. Acesso em: 10 jan. 2020. 
CAVALLEIRO, Eliane (org.). Racismo e anti-racismo na educação: repensando nossa escola. São Paulo: Selo Negro, 2001.

DA MATTA, Roberto. O que faz brasil, Brasil?. Rio de Janeiro: Rocco, 1986.

FANON, Frantz. Peles negras, máscaras brancas. Salvador: EDUFBA, 2008.

HARRIS, Marvin. Padrões raciais nas Américas. Rio de Janeiro: Civilização Brasileira, 1967.

MUNANGA, Kabengele. Negritude: usos e sentidos. São Paulo: Editora Ática, 1986.

MUNANGA, Kabengele. Rediscutindo a mestiçagem no Brasil: identidade nacional versus identidade negra. 3. ed. Belo Horizonte: Autêntica, 2008.

MUNANGA, Kabengele; GOMES, Nilma (org.). O negro no Brasil de hoje. São Paulo: Global, 2006.

NASCIMENTO, Abdias do. Processo de um racismo mascarado. Rio de Janeiro: Paz e Terra, 1978.

ROQUETTE-PINTO, Edgar. Ensaios de Antropologia Brasiliana. Rio de Janeiro: Editora Nacional, 1978.

RODRIGUES, Nina (1894). As raças humanas e a responsabilidade penal no Brasil. 3. ed. São Paulo: Cia Editora Nacional, 1938.

SILVA, Tomaz Tadeu (org.). Identidade e diferença: a perspectiva dos estudos culturais. 14. ed. Petrópolis: Vozes, 2014.

TORRES, Alberto. A organização nacional Brasília. DF: EdUnB, 1982.

Recebido em 29 de Junho de 2018 Aprovado em 10 de Junho de 2020 